\title{
UNDERSTANDING SAMPLING BY CHILEAN SECONDARY SCHOOL STUDENTS
}

\author{
KAREN RUIZ REYES \\ Universidad de Granada \\ karenruizreyes@gmail.com \\ JOSÉ MIGUEL CONTRERAS GARCÍA \\ Universidad de Granada \\ jmcontreras@ugr.es
}

\begin{abstract}
In statistical inference, importance of sampling is recognized as one of its key concepts, which has allowed its incorporation internationally in different curricular guidelines and specifically in the Chilean curriculum, since the first notions of sampling are introduced in $7^{\text {th }}$ Grade. This paper presents an analysis of the responses to an open-ended written questionnaire, designed to evaluate understanding of sampling, that was applied to a sample of 1,241 Chilean secondary students of $8^{\text {th }}, 10^{\text {th }}$ and $12^{\text {th }}$ Grades in six different secondary schools. A mixed methodology was used, with qualitative description of responses and a quantitative analysis of their frequencies. The results reflect outstanding difficulties in the use of elements related to sampling and its properties in different problem situations. For example, students can distinguish the concept of sample in contexts close to their experiences; but when faced with different sampling methods, they are not able to identify biases associated to sample selection. Thus, when deciding if a sample is representative, they mostly identify cases in which the given sample is not.
\end{abstract}

Keywords: Statistics education research; Sampling; Understanding; Statistical inference; Secondary education

\section{INTRODUCTION}

Through the analysis of different curricular guidelines from Spain, the United States and Chile (MEC, 2015; CCSSI, 2010; MINEDUC, 2009; 2012; 2015a) it is possible to observe that the teaching of statistics focuses, mainly, on descriptive concepts during the first school years, while inferential topics are being taught to last years of secondary school or to university courses. Nowadays, some mathematics education researchers (Batanero, 2013; Makar \& Ben-Zvi, 2011; Ben-Zvi, Bakker, \& Makar, 2015) highlight the importance of the foundations of statistical reasoning, which suggests a wider and deeper role of statistics within mathematical school instruction.

In relation to samples, Burrill and Biehler (2011) stated that sampling theory studies how samples and their properties are selected to draw unquestionable conclusions. Reaching an understanding of sampling as a fundamental concept in inference is indispensable to study hypothesis testing and confidence intervals.

The Chilean Curricular Framework (MINEDUC, 2009, 2012, 2015) establishes that primary education includes eight grades, while secondary education includes four grades. During the first primary school years, topics of descriptive statistics are studied. This includes the use of certain terms as synonyms of sampling, such as data collection or data group to describe the datasets under study, but without linking these to a population. The sample concept is formally addressed in $7^{\text {th }}$ Grade (1213 years old) as a subset within the population. Furthermore, concepts such as intuitive ideas of representativeness of sample, its randomness, and the possibility to estimate results from it, are studied.

In $10^{\text {th }}$ Grade (15-16 years old) additional concepts are studied, such as sample size, different counting techniques (permutations, variations and combinations) in randomization, with and without replacement. Finally, in $12^{\text {th }}$ Grade (17-18 years old), students make conjectures for the distribution type to which of the samples means $\bar{x}_{n}$ (sized $n$ ) tends when $n$ increases, which is an introduction to sampling distribution notion and its relationship to normal distribution (MINEDUC, 2015). Ruiz-Reyes 
et al. (2017) provide a wider and more detailed description of the concepts related to sampling that are present in Chilean curricular framework, alongside comparison among other international curricular guidelines.

Despite the importance given to sampling as one of the elementary concepts of inferential statistics, Ben-Zvi et al. (2015) determined that less attention has been paid to research on the topic compared to other statistical concepts. Therefore, taking into account this information and the early presence of sample concepts in the Chilean curriculum, there is the need to carry out an exploratory study to assess secondary school students' understanding of sampling, to provide information about the Chilean context, where previous studies on this topic have not been carried out.

This paper focuses on the research question: What do Chilean secondary school students understand about sample and sampling? To answer this question, a questionnaire of six open-ended items was elaborated and applied (see Appendix). The results provided by a sample of 1,241 Chilean secondary school students are detailed in the Result section of this report.

\section{BACKGROUND}

Watson and Moritz (2000) evidence that students from $3^{\text {rd }}$ Grade possess very elementary and particular notions about sample, specifically, of ideas derived from daily life experiences with sampling products (e.g., in a supermarket). Also, the students' conclusions on population were drawn from really small sample data, with no concern for bias in the sample selection method. Students from $6^{\text {th }}$ Grade tended to formulate varying beliefs about the sample size and the sampling method similar to the students from $9^{\text {th }}$ Grade who considered variation in the population; that is, they needed to have a sample that was big and representative enough. However, very often the students did not identify bias associated to the sample selection method.

A study on secondary school students' reasoning about sampling was developed by Watson (2004) through longitudinal interviews over 3 or 4 years with 38 students from $6^{\text {th }}$ to $12^{\text {th }}$ Grade $(11-18$ years old). This study evidenced that students prefered samples selected out of a biased process; that is, voluntarily delivered purposeful samples, over random samples. The students' responses, in general, improved gradually from the first to the last interview. From another study, Watson (2004) and Harradine et al. (2011) argued that students had difficulties with the idea of variability in populations, were overly confident with small samples, and did not consider the importance of sample size when drawing random samples.

The study performed by Meletiou-Mavrotheris and Paparistodemou (2015) analyzed the informal inferential reasoning of 69 students from $6^{\text {th }}$ Grade (11 years old) about the following concepts: sample, sample size, sampling method, and bias. Eighty five percent of students had heard the word sample in contexts unrelated to school (a shop, a pharmacy, etc.); however, almost half of them (46\%) did not explain the concept or gave an incomplete answer. Forty percent of the students provided definitions reflecting the idea of "a part", without the associated whole that characterizes the sample-population relationship or referred to it as "a test of something"; only twelve percent of the students provided more elaborate answers and recognized the part-whole relationship between sample and population.

\section{THEORETICAL FRAMEWORK}

The guidelines proposed by Zieffler et al. (2008) define Informal Inferential Reasoning (IIR) as: "The way in which students use their informal statistical knowledge to make arguments to support inferences about unknown populations based on observed samples" (p. 44). Additionally, these researchers pointed at three components of IIR to be considered:

1) Making judgments, claims, or predictions about populations based on samples, but not using formal statistical procedures and methods (e.g., $p$-value, $t$ tests) (p. 45);

For example, a researcher might ask whether the student made reasonable inferences about one or more populations based on one or more samples (p. 53).

2) Drawing on, utilizing, and integrating prior knowledge ..., to the extent that this knowledge is available (p. 45); 
For example, a researcher might ask how the student used and integrated informal knowledge (e.g., everyday knowledge of the problem context, prior knowledge about statistical concepts, real world knowledge and experience, and statistical language) in making inferences (p. 53).

3) Articulating evidence-based arguments for judgments, claims, or predictions about populations based on samples (p. 45).

For example, a researcher might ask how the student has used evidence to support his/her arguments in making inferences, and also, how well the evidence used supported the inferences made (p. 53).

\section{METHODOLOGY}

In this study, a mixed method was used (Hernández et al., 2014) to analyze data collected from a questionnaire. The analysis included a qualitative component, since there is a description of the responses provided by the students; and a descriptive quantitative analysis, specifically through tables that summarize the results of main variables considered in this research.

Six open-question items - validated by experts - were applied, which were based on some of the studies described previously in the Background section. In Table 1 we assigned the reference to the source from which each question was adapted, including the questions that were prepared by the authors of the present research. Five groups of questions were used (see Table 1), which had the purpose of measuring some of the aspects related to sampling. In total, the questionnaire had 20 questions distributed among the six items proposed (see Appendix). From the expert revision performed, for each question we established the analysis categories a priori, based on the expected correct answer for all the six items of the questionnaire. These will be described next, and their main features will be detailed in the frequency tables in the Results section.

Table 1. Reference studies

\begin{tabular}{|c|c|c|c|}
\hline Group & Objective & Item & Source \\
\hline 1 & $\begin{array}{l}\text { Understand the definition of } \\
\text { sample }\end{array}$ & $\begin{array}{l}1 \\
2\end{array}$ & $\begin{array}{l}\text { Watson (2004) } \\
\text { Meletiou-Mavrotheris \& Paparistodemou (2015) }\end{array}$ \\
\hline 2 & Suggest a sampling method & 3 & Prepared by the authors \\
\hline 3 & $\begin{array}{l}\text { Decide whether a sample is } \\
\text { representative }\end{array}$ & 4 & Del Valle et al. (2013) \\
\hline 4 & $\begin{array}{l}\text { Identify the sample and the } \\
\text { population }\end{array}$ & 5 & Muñoz et al. (2013) \\
\hline 5 & $\begin{array}{l}\text { Obtain all the possible } \\
\text { samples in a finite population }\end{array}$ & 6 & Prepared by the authors \\
\hline
\end{tabular}

For Item 1 (see Appendix), it is expected that students are able to explain in their own words what is understood by sample and mention any context in which the concept has been heard. The answer is considered correct if the student states any of the following situations: 1) Yes. It is a part of a bigger whole; 2) Yes. Gives examples in context but does not explain meaning; 3) Yes. When something is given to test.

For Item 2 (see Appendix), students are requested to apply the concept of sampling and its representativeness in a contextualized situation, with the purpose to evaluate whether they understand the concept of sample. Correct answers for question 1 include characterizing a sample "as a subset of a population", or that it corresponds to "a group of Chilean secondary school students." For question 2 , some reasons considered correct can include "because it is difficult to survey everybody"; "because it is an expensive process"; and "because it is time-consuming." Finally, for question 3, the correct answer for the first part is "No, I don't agree with selecting only 10 students"; and for the second part they were expected to indicate the sample size they would choose.

Item 3 (see Appendix) asked students to suggest a sampling method from a known sample size but based on an unknown population size. The correct answer was mentioning some sampling method and justifying that choice. 
Item 4 (see Appendix) requested students determine whether the sample indicated was representative or not; in the second part, students justified their choice. In Table 2 correct answers for Item 4 are presented.

Table 2. Correct answers Item 4

\begin{tabular}{lll}
\hline Sample & Is it representative? & Why? \\
\hline 1 & Yes & Because they were chosen randomly \\
2 & No & Because only one group of users was surveyed \\
3 & No & Because it does not consider variability \\
\hline
\end{tabular}

In Item 5 (see appendix), students must be able to identify the population and sample for each of the provided sets of data. The correct answers for that item are presented in Table 3.

Table 3. Correct answers Item 5

\begin{tabular}{|c|c|}
\hline Population & Sample \\
\hline 1. All yogurt units manufactured & 1. A determined number of each flavor \\
\hline $\begin{array}{l}\text { 2. The prices of the meat varieties at the } \\
\text { butchery }\end{array}$ & $\begin{array}{l}\text { 2. The prices of a variety of meats (beef, } \\
\text { fish, poultry) }\end{array}$ \\
\hline 3. All the ants in the insectarium & $\begin{array}{l}\text { 3. A certain amount of ants from the } \\
\text { insectarium }\end{array}$ \\
\hline 4. All the cities of the country & 4. One city per region \\
\hline
\end{tabular}

Item 6 (see Appendix) asks students to write down, all the different samples (with and without replacement) can be get, from a finite four elements population. In Table 4, the correct answers for Item 6 are specified.

Table 4. Correct answers Item 6

\begin{tabular}{ll}
\hline Samples with replacement & Samples without replacement \\
\hline $1-2 ; 2-1 ; 3-1 ; 4-1$. & $1-2 ; 2-3$. \\
$1-3 ; 2-3 ; 3-2 ; 4-2$. & $1-3 ; 2-4$. \\
$1-4 ; 2-4 ; 3-4 ; 4-3$. & $1-4 ; 3-4$. \\
\hline
\end{tabular}

For all the items, any answers that do not fit in the above mentioned criteria will be considered as incorrect.

\subsection{PARTICIPANTS AND CONTEXT}

In this study, the sample was formed by 1,241 Chilean students; $274(22.1 \%)$ from $8^{\text {th }}$ Grade $(13-$ 14 years old); 529 (42.6\%) from $10^{\text {th }}$ Grade (15-16 years old); and $438(35.3 \%)$ from $12^{\text {th }}$ Grade (1718 years old). The students attended six different secondary schools in the city of Osorno, Chile during the first semester of 2018. Out of these, $132(10.6 \%)$ attended private schools, $411(33.1 \%)$ attended semi-private schools, and $698(56.2 \%)$ attended public schools. The group was comprised of 690 (55.6\%) females and $551(44.4 \%)$ males.

The students answered the questionnaires in writing. They were given 45 minutes and it was administered as an activity that was part of their regular Maths lessons, with one of the researchers present, who explained the objective of the questionnaire and clarified possible doubts about its completion. It must also be said that, at the time of administering the questionnaire, neither teachers in charge in each class nor participating students were asked if they had received previous instruction on sampling, since this aspect was not part of the research objective. As mentioned above, although the Chilean curriculum includes the sample concept in $7^{\text {th }}$ Grade, we cannot state that these participating students had received prior instruction on this subject. 


\section{RESULTS}

The results of the study are described through the analysis of the students' responses to each item of the questionnaire (see Appendix). We present their ideas and the percentages of correct and incorrect answer per question.

The diversity of responses given for Item 1 (see Appendix) is detailed in Table 5. A low percentage did not answer (1.5\%) or had not heard about that concept $(2.1 \%)$; while responses from $96 \%$ of the students confirmed they had heard the word sample previously. When the students answered that a sample is part of a bigger whole, it was observed that the percentage of the answer increased gradually as the age of the students increased. Although, most students affirmed to have heard the word sample, only $43.8 \%$ provided examples in several contexts, mostly without explaining its meaning.

Table 5. Analysis of answers Item 1

\begin{tabular}{|c|c|c|c|c|}
\hline $\begin{array}{l}\text { Class } \\
\text { Answers }\end{array}$ & $\begin{array}{l}8^{\text {th }} \text { Grade } \\
n(\%)\end{array}$ & $\begin{array}{l}10^{\text {th }} \text { Grade } \\
n(\%)\end{array}$ & $\begin{array}{l}12^{\text {th }} \text { Grade } \\
n(\%)\end{array}$ & Total \\
\hline No answer. & $5(0.4)$ & $8(0.6)$ & $5(0.4)$ & $18(1.5)$ \\
\hline No. Never. & $7(0.6)$ & $15(1.2)$ & $4(0.3)$ & $26(2.1)$ \\
\hline Yes. It is part of a bigger whole. & $63(5.1)$ & $134(10.8)$ & $166(13.4)$ & $363(29.3)$ \\
\hline $\begin{array}{l}\text { Yes. Gives examples in context but does } \\
\text { not explain meaning. }\end{array}$ & $133(10.7)$ & $270(21.8)$ & $141(11.4)$ & $544(43.8)$ \\
\hline $\begin{array}{l}\text { Yes. Gives explanation without any solid } \\
\text { basis. }\end{array}$ & $66(5.3)$ & $81(6.5)$ & $106(8.5)$ & $253(20.4)$ \\
\hline Yes. When something is given to test. & $0(0)$ & $21(1.7)$ & $16(1.3)$ & $37(3)$ \\
\hline Total & 274 & 529 & 438 & 1241 \\
\hline
\end{tabular}

Comparing answers per class (see Table 6), it was observed that the highest percentage of correct answers corresponded to students from $10^{\text {th }}$ Grade $(34.2 \%)$, followed by students from $12^{\text {th }}$ Grade (26\%); and lastly by students from $8^{\text {th }}$ Grade (15.8\%).

Table 6. Correct and incorrect answers Item 1

\begin{tabular}{lllll}
\hline Class & $8^{\text {th }}$ Grade & $\begin{array}{l}10^{\text {th }} \text { Grade } \\
n(\%)\end{array}$ & $\begin{array}{l}12^{\text {th }} \text { Grade } \\
n(\%)\end{array}$ & Total $(\%)$ \\
\hline Answers & $n(\%)$ & $104(8.4)$ & $115(9.3)$ & $297(23.9)$ \\
Correct & $78(6.3)$ & $425(34.2)$ & $323(26)$ & $944(76.1)$ \\
\hline Total & 274 & 529 & 438 & 1241 \\
\hline
\end{tabular}

In sum, 944 students $(76.1 \%)$ gave a correct answer by indicating they had heard the word sample in some context (health center, supermarket, shop, pharmacy, etc.) but not necessarily in a Math lesson, which means their responses were based on informal statistical aspects. Conversely, 297 (23.9\%) provided an incorrect answer, by not answering or giving examples in unclear contexts.

For the first question in Item 2 (see Appendix), students manifested they had a relatively clear idea of the concept of sample in a context that was close to their own reality, given that $27(2.2 \%)$ students did not answer, as seen in Table 7. It is observed that $12.8 \%$ answer incorrectly, while $83.8 \%(1,040)$ mentioned ideas such as a small part, a percentage, or an amount, and only 15 students (1.2\%) give a more accurate definition, that is, the answer was a subset of a population. To sum up, $85 \%$ of the students answer this item correctly. The analysis of responses per class shows that $16.9 \%$ of students from $8^{\text {th }}$ Grade answered correctly; this percentage increased when considering students from $10^{\text {th }}$ Grade $(35.8 \%)$ and, similarly, $12^{\text {th }}$ Grade $(32.2 \%)$. 
Table 7. Analysis of answers Item 2, question 1

\begin{tabular}{lllll}
\hline Class & $\begin{array}{l}8^{\text {th }} \text { Grade } \\
n(\%)\end{array}$ & $\begin{array}{l}10^{\text {th }} \text { Grade } \\
n(\%)\end{array}$ & $\begin{array}{l}12^{\text {th }} \text { Grade } \\
n(\%)\end{array}$ & Total $(\%)$ \\
\hline No answers & $6(0.5)$ & $15(1.2)$ & $6(0.5)$ & $27(2.2)$ \\
Incorrect & $57(4.6)$ & $70(5.6)$ & $32(2.6)$ & $159(12.8)$ \\
A part, a small part & $153(12.3)$ & $289(23.3)$ & $262(21.1)$ & $704(56.7)$ \\
A percentage & $16(1.3)$ & $42(3.4)$ & $30(2.4)$ & $88(7.1)$ \\
An amount & $39(3.1)$ & $107(8.6)$ & $102(8.2)$ & $248(20)$ \\
A subset from a population & $3(0.2)$ & $6(0.5)$ & $6(0.5)$ & $15(1.2)$ \\
\hline Total & 274 & 529 & 438 & 1241 \\
\hline
\end{tabular}

In the case of question 2 (see Table 8), 65.5\% (812) of students have a clearer idea of the factors that are relevant when choosing a sample from a population; for example, they mentioned ideas about time-consuming processes, costs of the survey, or access to interview the total population. This means that a high percentage of the students took into consideration the factors that affected the selection of representative samples; while 34\% (429) answered incorrectly or gave no answer. The main reason mentioned to select a sample is because it is difficult to survey everybody (31.3\%); as a second choice, they said that it would be time-consuming (21.2\%). Students from $10^{\text {th }}$ Grade were more inclined to choose these answers, followed by students from $12^{\text {th }}$ Grade and lastly, by $8^{\text {th }}$ Grade.

Table 8. Analysis answers Item 2, question 2

\begin{tabular}{lllll}
\hline Class & $8^{\text {th }}$ Grade & $10^{\text {th }}$ Grade & $12^{\text {th }}$ Grade & \\
$n(\%)$ & $n(\%)$ & $n(\%)$ & Total $(\%)$ \\
\hline Answers & $14(1.1)$ & $22(1.8)$ & $14(1.1)$ & $50(4)$ \\
No answer & $104(8.4)$ & $169(13.6)$ & $106(8.5)$ & $379(30.5)$ \\
Bncorrect & $79(6.4)$ & $165(13.3)$ & $145(11.6)$ & $389(31.3)$ \\
Because it is difficult to ask everyone & $2(0.2)$ & $4(0.3)$ & $1(0.08)$ & $7(0.6)$ \\
Because it is expensive & $60(4.8)$ & $118(9.5)$ & $85(6.8)$ & $263(21.2)$ \\
It is faster or easier & $3(0.2)$ & $18(1.5)$ & $41(3.3)$ & $62(5)$ \\
$\begin{array}{l}\text { Because the same results can be } \\
\text { obtained }\end{array}$ & $12(1)$ & $33(2.7)$ & $46(3.7)$ & $91(7.3)$ \\
\hline Total & & & & \\
\hline
\end{tabular}

In the answers to Question 3 of Item 2 (see Table 9), it is observed that $19.8 \%$ do not answer; $35.6 \%$ disagree with choosing "only 10 students" as a sample; and $44.6 \%$ agree with the statement proposed.

Table 9. Analysis of answers Item 3, question 3 a

\begin{tabular}{lllll}
\hline Class & $8^{\text {th }}$ Grade & $10^{\text {th }}$ Grade & $12^{\text {th }}$ Grade & \\
Answers & $n(\%)$ & $n(\%)$ & $n(\%)$ & Total $(\%)$ \\
\hline No answer & $69(5.6)$ & $91(7.3)$ & $86(6.9)$ & $246(19.8)$ \\
I disagree & $79(6.4)$ & $203(16.3)$ & $160(12.9)$ & $442(35.6)$ \\
I agree & $126(10.2)$ & $235(19)$ & $192(15.4)$ & $553(44.6)$ \\
\hline Total & 274 & 529 & 438 & 1241 \\
\hline
\end{tabular}

For this question, only $35.6 \%$ answered correctly. Although, in the previous questions, the students evidenced an elementary level of comprehension of sample and the limitations to perform a study that surveys at total population - when required to quantify the subjects of their sample, their conclusions were not really accurate. It could be inferred that these answers were influenced by the fact that the population under study was unknown, which made it hard to quantify and may lead to mistakes when interpreting the question. Again, it was observed that students from $10^{\text {th }}$ Grade are the ones who 
answered this question best, followed by $12^{\text {th }}$ Grade; and lastly, $8^{\text {th }}$ Grade.

For the second part of question 3, How many would you choose? (see Table 10), 34.3\% of the studnets indicated they would choose " 10 students", just like the first part of the question stated. Another $36.8 \%$ of the studnets pointed out that they would consider "more students" depending on the total number of interviewed students, or the total number of schools involved to the study; and only 9.2\% consider that all Chilean secondary school students should be interviewed, which showed they did not use the reasoning provided in the previous question about selecting a representative sample.

It was observed that $56.6 \%$ of students affirmed that a sample bigger than 10 students should be selected (considering all the reasons presented); although they do not refer expressly to representativeness. Some students some considered the sample should be selected randomly, or according to the total number of interviewed students. We observed that $22.8 \%$ of students from $10^{\text {th }}$ Grade; $21.3 \%$ from $12^{\text {th }}$ Grade, and $12.5 \%$ from $8^{\text {th }}$ Grade answered the question correctly.

Table 10. Analysis of answers Item 3, question $3 b$

\begin{tabular}{lllll}
\hline Class & $8^{\text {th }}$ Grade & $10^{\text {th }}$ Grade & $12^{\text {th }}$ Grade & \\
Answers & $n(\%)$ & $n(\%)$ & $n(\%)$ & Total $(\%)$ \\
\hline No answer & $15(1.2)$ & $29(2.3)$ & $23(1.9)$ & $67(5.4)$ \\
10 students & $91(7.3)$ & $198(16)$ & $137(11)$ & $426(34.3)$ \\
More students & $96(7.7)$ & $187(15.1)$ & $174(14)$ & $457(36.8)$ \\
$50 \%$ & $13(1.1)$ & $27(2.2)$ & $21(1.7)$ & $61(4.9)$ \\
All of them & $35(2.8)$ & $45(3.6)$ & $34(2.7)$ & $114(9.2)$ \\
Depends on total & $11(0.9)$ & $22(1.8)$ & $35(2.8)$ & $68(5.5)$ \\
Randomly & $0(0)$ & $1(0.1)$ & $2(0.1)$ & $3(0.2)$ \\
Less than 10 & $13(1.1)$ & $20(1.6)$ & $12(1)$ & $45(3.6)$ \\
\hline Total & 274 & 529 & 438 & 1241 \\
\hline
\end{tabular}

When students were asked to suggest how they may select a sample (with a sample size given), from a contextual situation close to their reality (Item 3, see Appendix), it was observed that $38.9 \%$ of them mentioned a sampling method, but do not justify its choice; and 5.7\% refered to selecting a biased sample; for example, they chose a group belonging to a particular school level, or considered other common characteristics, such as sex or age of the participants (see Table 11). Overall, Item 3 shows a high percentage of incorrect answers (59.3\%); only $40.7 \%$ of students answer correctly, indicating a sampling method and justifying its choice. When the results are organized forr this item per class, it was noted that students from $10^{\text {th }}$ Grade $(22.2 \%)$, followed by $8^{\text {th }}$ Grade students $(9.8 \%)$ and, finally, by $12^{\text {th }}$ Grade students (8.7\%) answered correctly. It can be argued that the highest difficulty to answering this question arises from not indicating explicitly the total number of students of the school (population) in the statement, which may have prevented them from understanding the situation stated in the question. Additionally, as the last curricular changes for $10^{\text {th }}$ Grade do no longer include sampling methods (MINEDUC, 2015), this might be a factor that influences the high percentage of incorrect answers.

Table 11. Analysis of answers Item 3

\begin{tabular}{|c|c|c|c|c|}
\hline $\begin{array}{l}\text { Class } \\
\text { Answer }\end{array}$ & $\begin{array}{l}8^{\text {th }} \text { Grade } \\
n(\%)\end{array}$ & $\begin{array}{l}10^{\text {th }} \text { Grade } \\
n(\%)\end{array}$ & $\begin{array}{l}12^{\text {th }} \text { Grade } \\
n(\%)\end{array}$ & Total $(\%)$ \\
\hline No answer & $32(2.6)$ & $101(8.1)$ & 49 (4) & $182(14.7)$ \\
\hline $\begin{array}{l}\text { Mentions a sampling method, does } \\
\text { not justify answer }\end{array}$ & $112(9)$ & $124(10)$ & 247 (19.9) & $483(38.9)$ \\
\hline $\begin{array}{l}\text { Mentions obtaining a sample from } \\
\text { a biased group (some particular } \\
\text { feature) }\end{array}$ & $8(0.7)$ & $29(2.3)$ & $34(2.7)$ & $71(5.7)$ \\
\hline $\begin{array}{l}\text { Uses any sampling method and } \\
\text { justifies answer }\end{array}$ & $122(9.8)$ & $275(22.2)$ & $108(8.7)$ & $505(40.7)$ \\
\hline Total & 274 & 529 & 438 & 1241 \\
\hline
\end{tabular}


Item 4 (see Appendix) was adapted from an activity extracted from a textbook (Del Valle et al., 2013, p. 247) in which students were to indicate if the given sample was representative or not, as well as to justify their responses. In Table 12, the correct answer percentages are presented to summarize the data.

Table 12. Analysis of answers Item 4 (correct answers)

\begin{tabular}{lllll}
\hline Class & $\begin{array}{l}8^{\text {th }} \text { Grade } \\
n(\%)\end{array}$ & $\begin{array}{l}10^{\text {th }} \text { Grade } \\
n(\%)\end{array}$ & $\begin{array}{l}12^{\text {th }} \text { Grade } \\
n(\%)\end{array}$ & Total $(\%)$ \\
\hline Sample 1. & $118(9.5)$ & $193(15.6)$ & $165(13.3)$ & $476(38.4)$ \\
Sample 2. & $99(8)$ & $217(17.4)$ & $198(16)$ & $514(41.4)$ \\
Sample 3. & $114(9.2)$ & $213(17.2)$ & $200(16.1)$ & $527(42.5)$ \\
\hline
\end{tabular}

In the first sample, only $38.4 \%$ (476 students) answered correctly, pointing out that the sample is representative, in a situation that involves a random sampling method. In the second one, only $41.4 \%$ (514 students) answered that the given sample is not representative, because it is a restricted sampling method, which implies that subjects are chosen by biased process and it is not a representative sample of the population. Finally, in the third sample, only 42.5\% (527 students) answered that the sample is not representative, since it used a self-selected sampling method, which showed that subject selection choice poses problems for identifying whether it is representative or not, as it considers subjects with specific characteristics, without considering all subjects of population under study. It was observed that the students recognized mostly non-representative samples; but in the first sample they do not identify that it is a random sampling method. They focused only on the given sample size and did not consider relevant that it had been selected randomly, resulting in incorrect answers (61.6\% or 765 students).

Among the explanations to justify the answers to the first sample, students mentioned the following: because a third of the population was chosen; because it was a random sample; and half of the population should be chosen. For the second sample, they point to reasons like: they should survey more people; because only one group of users are surveyed; and they should be surveyed at different times. Finally, for the third sample, the explanations indicated are: because the diversity of heights should be considered; variability was not considered; and all students should be measured to get an average.

Item 5 (see Appendix) was adapted from an activity from a textbook (Muñoz et al., 2013, p. 275). The item required students to indicate the population and a possible sample for each statement. In Table 13 the percentages of correct and incorrect answers are presented to facilitate the readers' analysis. The majority of students answered Item 5 incorrectly (see Table 13), both to identify population and sample requested, showing that they had problems recognizing those concepts in contexts far removed from the school reality. In addition, they do not identify the difference between the part-whole relationship in the contexts mentioned in the item statement. From the analysis of responses to Item 5 per class, it was observed that $12^{\text {th }}$ Grade students obtained better results in identifying population, which decreased in the other classes. The same phenomenon occured for the fourth sample; whereas for the first three samples, those who obtain more correct answers were $10^{\text {th }}$ Grade students, followed by $12^{\text {th }}$ Grade students. The students who obtained the lowest results were those in $8^{\text {th }}$ Grade.

Table 13. Analysis of answers Item 5

\begin{tabular}{lllll}
\hline & \multicolumn{2}{c}{ Population } & \multicolumn{2}{c}{ Sample } \\
& Answer & \multicolumn{2}{c}{ Answer } \\
& Incorrect & Correct & Incorrect & Correct \\
& $n(\%)$ & $n(\%)$ & $n(\%)$ & $n(\%)$ \\
\hline Data set 1. & $856(69)$ & $385(31)$ & $897(72.3)$ & $344(27.7)$ \\
Data set 2. & $976(78.6)$ & $265(21.4)$ & $974(78.5)$ & $267(21.5)$ \\
Data set 3. & $785(63.3)$ & $456(36.7)$ & $879(70.8)$ & $362(29.2)$ \\
Data set 4. & $1114(89.8)$ & $127(10.2)$ & $1149(92.6)$ & $92(7.4)$ \\
\hline
\end{tabular}


Finally, in Item 6 (see Appendix), only 22.4\% answered this question correctly, writing both list of samples requested; $25.8 \%$ gave partially correct answers, writing only one of the list of samples requested (i.e., writing the sample with replacement or the sample without replacement); $14 \%$ wrote the sample with (or without) replacement incompletely, with some missing elements; and $37.8 \%$ did not answer (see Table 14). When analysing the results from Item 6 by correct answer and class, it was perceived that a higher number of $10^{\text {th }}$ Grade students answer correctly $(11.4 \%)$, followed by $12^{\text {th }}$ Grade students (7.7\%); and lastly by $8^{\text {th }}$ Grade students (3.3\%). Since this question involved combinations and permutation, we observed that some $12^{\text {th }}$ Grade students answered incorrectly because they confused the formula of the respective counting technique that should be used, as they do not identify that this formula only gives the number of elements that each sample should contain.

Table 14. Analysis of answers Item 6

\begin{tabular}{|c|c|c|c|c|}
\hline $\begin{array}{l}\text { Class } \\
\text { Answer }\end{array}$ & $\begin{array}{l}8^{\text {th }} \text { Grade } \\
n(\%)\end{array}$ & $\begin{array}{l}10^{\text {th }} \text { Grade } \\
n(\%)\end{array}$ & $\begin{array}{l}12^{\text {th }} \text { Grade } \\
n(\%)\end{array}$ & Total (\%) \\
\hline No answer & $104(8.4)$ & $221(17.8)$ & 144 (11.6) & $469(37.8)$ \\
\hline Writes list of samples with replacement & $70(5.6)$ & $86(6.9)$ & $116(9.4)$ & $272(21.9)$ \\
\hline $\begin{array}{l}\text { Writes incomplete list of samples with } \\
\text { replacement }\end{array}$ & $24(1.9)$ & $20(1.6)$ & $29(2.3)$ & $73(5.9)$ \\
\hline $\begin{array}{l}\text { Writes list of samples without } \\
\text { replacement }\end{array}$ & $10(0.8)$ & $22(1.8)$ & $16(1.3)$ & $48(3.9)$ \\
\hline $\begin{array}{l}\text { Writes incomplete list of samples without } \\
\text { replacement }\end{array}$ & $25(2)$ & $38(3.1)$ & $37(3)$ & $100(8.1)$ \\
\hline Writes both lists of samples & $41(3.3)$ & $142(11.4)$ & $96(7.7)$ & $279(22.4)$ \\
\hline Total & 274 & 529 & 438 & $1241(100)$ \\
\hline
\end{tabular}

\section{DISCUSSION}

The findings of this exploratory study have allowed us to identify and characterize what Chilean secondary school students understand about samples and sampling, from the perspective of Informal Inferential Reasoning (IIR). Students, at the moment of elaborating their arguments, do not necessarily use formal statistical methods, in addition, their answers may (or not) contain concepts or formal statistical language (Zieffler et al., 2008), as it has been exposed in the analyses presented in the Results section. The responses obtained by the sample of 1,241 Chilean secondary school students provide useful information on their understanding of sampling, as well as on the main difficulties related to it.

The results indicate that students distinguish the sample concept in contexts close to their experiences (health, science, shopping, etc.), with very few students giving more elaborate responses when connected to a mathematical context; that is, they use the randomness concept in their arguments. Only fifteen students defined sample as a subset of the population. Similar results were obtained in the studies by Watson and Moritz (2000) and Meletiou-Mavrotheris and Paparistodemou (2015).

Another aspect to consider is that students are susceptible to insensitivity to sample size (Tversky \& Kahneman, 1974), that is, they assume that the selected sample, regardless of its size, always represents the population to which it belongs, which induces serious errors of interpretation in statistical analysis. Furthermore, as Kahneman et al. (1982) indicated, this type of person also believes in the law of small numbers; in other words, they believe that when selecting samples that are not large enough, the sample distribution is distributed in the same way as the distribution of the population, regardless of the sample size. When we asked the students to identify the sample of a study in a context closer to their reality, some inconsistencies in their responses were observed. For example, they were able to identify the limitations that may lead a researcher to survey all subjects in a given population, but when they were to suggest a sample or when we asked what sample size they would choose, $43.4 \%$ of the students in our study responded incorrectly.

When the students tried to suggest a sampling method, only $38.9 \%$ gave a response, but did not justify their selection method. It should be noted that most students do not provide a sampling method 
because in the problem statement (Item 3, see Appendix), the total number of students (unknown population) is not mentioned.

When deciding if a sample is representative, students mostly distinguish cases in which the given sample is not representative; but in the first case, they do not distinguish that it is a random sampling method, leading to the mistake of believing that this sample is not representative of the population. In sum, they focused on the sample size but did not recognize randomness as an important element to be considered in the sampling method. In this sense, in relation to the role of context in sampling reasoning, Wroughton et al. (2013) suggested that students, who have strong opinions on a topic, will assess the validity of a study's conclusions based on whether those conclusions match their opinion, rather than analyzing the quality of the sampling method used by means of statistical principles.

When we asked the students to identify the population and the sample, the students answered incorrectly. We believe that, because the contexts exposed in this activity were adapted from a school textbook, it was unknown to the students, which prevented an easy identification of the part-whole relationship in the elements that made up the population or the sample of each case. Finally, when asked to obtain as many samples (with and without replacement) as possible from a finite population, only $22.4 \%$ of students responded correctly, while $25.8 \%$ entered only one of the listings requested.

As limitations of this study, we can point out that the wording of Item 5 of the questionnaire should be improved (see Appendix), using other contexts closer to the students' experiences. In addition, it would be interesting to deepen the analysis of the arguments provided by the students, using some of the categories mentioned by Watson (2004), as well as, to complement the results presented here with comparisons between the different types of educational centers.

For future research, the design and implementation of a teaching experiment on sampling could be considered, to promote Informal Inferential Reasoning (IIR) using the three components suggested by Zieffler et al. (2008), as well as include other types of tasks suggested to extend IIR. For example, simulation-supported activities such as "Growing Samples" might be included, because in this approach, students are gradually introduced to increasing sample sizes that are taken from the same population; and for each sample, they are asked to make sense of it and make an informal inference (Ben-Zvi et al., 2015). In addition to the application of this questionnaire, another session to analyze answers offered in a group discussion with the students may be useful. There is the potential to extend the study with some interviews, to check more closely the ideas that the students have of these concepts, since sometimes, the students in this study may not have expressed all their knowledge in the written tasks. It would also be interesting to apply the questionnaire in other Latin American contexts, which would allow for comparison with the findings presented in this paper.

Likewise, the understanding of sampling could be studied with future mathematics teachers because sampling is a basic concept to statistical inference, and it is present in the Chilean school curriculum. It is imperative that future mathematics teachers understand this concept. Considering that these results, although they are focused on a particular context of secondary education, form a precedent to continue contributing to the field of research in statistical education in the Latin American context, and specifically, in relation to informal statistical inference, since this line of research is still emerging in the Chilean context, in comparison with the research that has been developed already in the international field.

\section{ACKNOWLEDGEMENTS}

The present work was completed with funds from Project EDU2016-74848-P and the CONICYT Chile Scholarship (PFCHA 72160521).

\section{REFERENCES}

Batanero, C. (2013). Del análisis de datos a la inferencia: Reflexiones sobre la formación del razonamiento estadístico. [From data analysis to inference: Reflections on the formation of statistical reasoning] Cuadernos de Investigación y Formación en Educación Matemática, 11(8), 277-291.

Ben-Zvi, D., Bakker, A., \& Makar, K. (2015). Learning to reason from samples. Educational Studies in Mathematics, 88(3), 291-303. 
Burrill, G., \& Biehler, R. (2011). Fundamental statistical ideas in the school curriculum and in training teachers. In C. Batanero, G. Burrill \& C. Reading (Eds.), Teaching statistics in school mathematics: Challenges for teaching and teacher education. A Joint ICMI/IASE study (pp. 57-69). Springer.

CCSSI (2010). Common Core State Standards for Mathematics. National Governors Association Center for Best Practices and the Council of Chief State School Officers.

Del Valle, J., Muñoz, G., \& Santís, M. A. (2013). Matemática $1^{\circ}$ Medio. S.M.

Harradine, A., Batanero, C., \& Rossman, A. (2011). Students and teachers' knowledge of sampling and inference. In C. Batanero, G. Burrill \& C. Reading (Eds.), Teaching statistics in school mathematics: Challenges for teaching and teacher education. A Joint ICMI/IASE study (pp. 235246). Springer.

Hernández, R., Fernández, C., \& Baptista, P. (2014). Metodología de la investigación. [Methodology of the research] McGraw Hill.

Kahneman, D., Slovic, P., \& Tversky, A. (1982). Judgment under uncertainty: Heuristics and biases. Cambridge University Press.

Makar, K., \& Ben-Zvi, D. (2011). The role of context in developing reasoning about informal statistical inference. Mathematical Thinking and Learning, 13(1-2), 1-4.

MEC. (2015). Real Decreto 1105/2014, de 26 de diciembre, por el que se establece el currículo básico de la Educación Secundaria Obligatoria y del Bachillerato. [Royal Decree 1105/2014, of 26 December, establishing the basic curriculum for compulsory secondary education and the baccalaureate] Author.

Meletiou-Mavrotheris, M., \& Paparistodemou, E. (2015). Developing students' reasoning about samples and sampling in the context of informal inferences. Educational Studies in Mathematics, 88(3), 385-404.

Merino, R., Muñoz, V., Pérez, B., \& Rupin, P. (2015). Matemática $7^{\circ}$ Básico. S. M.

MINEDUC. (2009). Objetivos Fundamentales y Contenidos Mínimos Obligatorios de la Enseñanza Básica y Media. [Fundamental objectives and compulsory minimum contents of basic and secondary educaton] Unidad de Currículum y Evaluación.

MINEDUC. (2012). Bases Curriculares: Matemática, Educación Básica. [Curricular Bases: Mathematics, Basic Education]. Unidad de Currículum y Evaluación.

MINEDUC. (2015). Bases Curriculares: Matemática, Educación Media. [Curricular Bases: Mathematics, Secondary Education]. Unidad de Currículum y Evaluación.

Muñoz, G., Rupín, P., \& Jiménez, L. (2013). Matemáticas $2^{\circ}$ Medio. S. M.

Ruiz-Reyes, K., Begué, N., Batanero, C., \& Contreras, J. M. (2017). Un estudio comparado de los contenidos de muestreo en la Educación Secundaria Obligatoria en Chile. [A comparative study of sample contents in compulsory secondary education in Chile]. Educação Matemática Pesquisa, 19(3), 67-83.

Tversky, A., \& Kahneman, D. (1974). Judgement under uncertainty: Heuristics and biases. Science, 185(4157), 1124-1131. https://doi.org/10.1126/science.185.4157.1124

Watson, J. (2004). Developing reasoning about samples. In D. Ben-Zvi \& J. Garfield (Eds.), The challenge of developing statistical literacy, reasoning and thinking (pp. 277-294). Kluwer.

Watson, J. M., \& Moritz, J. B. (2000). Developing concepts of sampling. Journal for Research in Mathematics Education, 31(1), 44-70.

Wroughton, J. R., McGowan, H. M., Weiss, L. V., \& Cope, T. M. (2013). Exploring the role of context in students' understanding of sampling. Statistics Education Research Journal, 12(2), 32-58. https://doi.org/10.52041/serj.v12i2.303

Zieffler, A., Garfield, J., Delmas, R., \& Reading, C. (2008). A framework to support research on informal inferential reasoning. Statistics Education Research Journal, 7(2), 40-58. https://www.stat.auckland.ac.nz/ iase/serj/SERJ7(2)_Zieffler.pdf

KAREN RUIZ REYES

Universidad de Granada

SPAIN

karenruizreyes@gmail.com 


\section{APPENDIX}

Item 1: Have you heard the word sample before? Explain what it means to you.

Item 2: In a study conducted about exercising habits of Chilean secondary school students, some researchers interviewed a sample of them.

1. What is the meaning of sample in this sentence?

2. Why do you think the researchers selected a sample of students instead of asking all the participants?

3. Do you agree with the researchers selecting a sample of 10 students? How many would you select?

Item 3: Let's imagine that you want to know the percentage of children who come to your school using different means of transport: on foot, by car, bus, bike or any other. How would you select a sample of 50 students so the results represent the entire school?

Item 4: Analyze if the following samples are representative of the population under study and fill in the table with your answers.

\begin{tabular}{|l|l|l|}
\hline Sample & Is it representative? & Why? \\
\hline $1 . \quad 100$ students are selected & & \\
randomly out of 300 students & & \\
from a school to calculate the & & \\
population's grade average & & \\
\hline $\begin{array}{l}\text { The first } 100 \text { people who } \\
\text { take the subway in the morning }\end{array}$ & & \\
are surveyed on the subway & & \\
service quality shortest & & \\
\hline $\begin{array}{l}\text { 3. The tallest and she } \\
\text { children from a class are selected } \\
\text { to determine the students' } \\
\text { average height }\end{array}$ & & \\
\hline
\end{tabular}

Item 5: Determine the population in each case and a possible sample of it. Fill in the table with your answers.

\begin{tabular}{|l|l|l|}
\hline \multicolumn{1}{|c|}{ Data } & \multicolumn{1}{|c|}{ Population } & Sample \\
\hline $\begin{array}{l}\text { 1. A yogurt company wants to } \\
\text { research about the quality of its } \\
\text { products. }\end{array}$ & & \\
\hline $\begin{array}{l}\text { 2. Diego needs to know the price } \\
\text { of 1 kg of meat for a family meal. }\end{array}$ & & \\
\hline $\begin{array}{l}\text { 3. Ximena studies the size of ants } \\
\text { inhabiting an insectarium. }\end{array}$ & \\
\hline $\begin{array}{l}\text { 4. Daniel wants to know if a city } \\
\text { gets enough rain in order to start } \\
\text { a plantation. }\end{array}$ & & \\
\hline
\end{tabular}

Item 6: We have four books numbered 1, 2, 3 and 4. Write down all the possible samples of two books with and without replacement. 